\title{
The role of human resource management in the concept of sustainable enterprise development
}

\author{
Vlada Zhykharieva ${ }^{1}$, Olga Vlasenko $^{2 *}$, Inna Poznanska ${ }^{3}$, Maryna Matviienko ${ }^{4}$, and Mariia \\ Sokolova ${ }^{5}$ \\ 1,2,3,5 Odessa National Maritime University, Department of Economics and Finance, 34 Mechnikova, \\ 65029 Odessa, Ukraine \\ ${ }^{4}$ Odessa National Maritime University, Department of Entrepreneurship and Tourism, 34 \\ Mechnikova, 65029 Odessa, Ukraine
}

\begin{abstract}
In the article the sustainable development as the alternative concept of further transformation of the economic system in general and an enterprise in particular is considered. The concept of the sustainable development cycle of enterprise was improved by the authors; they specified the important role of human resources management in this cycle. The paper emphasizes the need to focus the human resources management not only on the operational activities' results, but also on increasing the employees' personal competitiveness and intensifying collaboration and mutual support to form a corporate knowledge due to developing corporate universities and E-learning systems aimed at continuous sustainable development of human resources. A significant attention in the concept of an enterprise sustainable development is paid to creation an effective human capital management strategy. This strategy should be focused on decomposition of the objectives in sustainable development, building a favourable organizational culture, developing business models that are based on effective communication with consumers, selecting the state-ofthe-art forms of business organization and doing business; this is including, but not limiting, to those that have emerged in the field of social business, which allow to move towards implementation of the main objectives of sustainable development.
\end{abstract}

\section{Introduction}

The modern economic development is inextricably linked with globalization, which covers all fields of human life, including social, political, cultural, and economic. The active implementation of information technologies and systems into economic entities' activities makes a positive contribution to strengthening communication links and accelerating the formation and transformation processes in the world community. Numerous financial crises and military conflicts have complicated the geopolitical situation, and thus significantly affected economy of most countries in the world. In this regard, such factors as instability, unpredictability and fierce competition are characteristic features of the current economic situation.

* Corresponding author: olga.vlasenko.mail@gmail.com 
These features affect not only a company's relations with the external business environment, but also affect an organization's internal processes. Focusing on traditional economic indicators and applying standard management methods in a turbulent modern environment is insufficient for an enterprise development. Obviously new approaches and management instruments are needed. The enterprises may require developing new management methods reflected in the sustainable development concept.

The Sustainable Development Concept originates from December 1983, when the International Commission on Environment and Development was established in accordance with the UN General Assembly's resolution 38/161. According to the UN Commission on Sustainable Development, the goal is to meet the needs of modern society without compromising the future generations' ability to meet their own needs. Therefore, the sustainable development theory is the alternative to the paradigm of economic growth, which frequently ignores the danger of extensive development model for environment [1].

The decisive world summit took place in Rio in 1992. Three major treaties were adopted [2] there, which outlined a clear basis for the Millennium Development Goals [3]. As a result of the UN Millennium Summit in 2000 and adoption of the UN Millennium Declaration, the above-mentioned Millennium Development Goals were adopted. It described the path of the humanity's development until 2015 [4].

In June 2012 leaders from around the world met again at Rio +20 Summit in order to sum up the Millennium Development Goals. They specified the fight against marginal poverty as a top priority, without which it would be impossible to complete complex tasks on other aspects of sustainable development. The meeting resulted in the transition from the Millennium Development Goals to the Sustainable Development Goals [5]. On the Fifth Anniversary of the UN Millennium Declaration on the Ways of Human Development, seventeen sustainable development goals by 2030 were formulated, including 169 sub-goals and 232 indicators [6].

The world community representatives have noted, above all, the extreme importance of the transition from the economic growth concept to the sustainable development concept not only as an instrument for further economic systems evolution, but also as a condition for the human society's survival in the future.

Thus, business management concepts should be developed taking into account the sustainable development paradigm that is based on environmental protection, human rights and freedoms, specifying the humanization features and society informatization, transformation of human resource management strategy, using new business forms based on collaboration and positive experience.

\section{Materials and Methods}

The donor-funded priority sustainable development goals were shown by an analysis of the Council of Europe's support for "Agenda for Sustainable Development 2030" from voluntary contributions (i.e. donations) $[7,8]$. It can be stated that due to the voluntary donations most support (47.2\%) was shown for the COE's program SDG-16 "Peace, Justice, and Powerful Institutions" (see Fig. 1).

Overall, donations have contributed to several other goals, including SDG-5 "Gender equality" (16.4\%), SDG-8 "Decent Work and Economic Growth" (10.2\%), SDG-3 "Good Health and Well-Being" (7\%), SDG-11 "Sustainable Cities and Communities" (5.2\%), and SDG-4 "Quality Education" (5.1\%). Total amount of voluntary donations has reached $€ 77,777,312$ [7. P. 12]. The voluntary donations distribution can determine the distribution of SDG priorities. In addition, it should be noted that SDG-8 "Decent Work and Economic Growth", which was ranked the third in terms of funding and thus it is a priority program not only in funding, but also in research. 


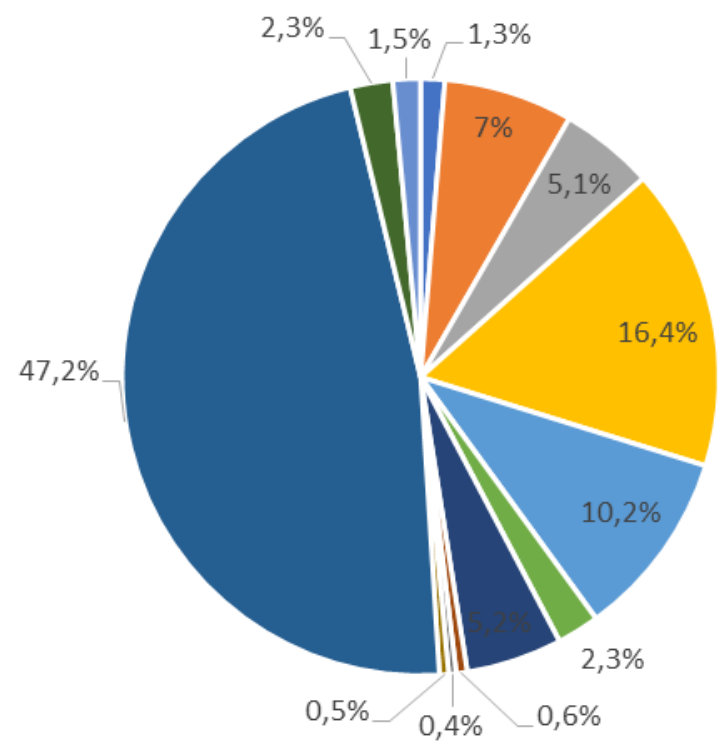

- SDG-1

- SDG-3

- SDG-4

- SDG-5

- SDG-8

- SDG-10

- SDG-11

- SDG-13

- SDG-14

- SDG-15

- SDG-16

- SDG-17

Fig. 1. Council of Europe support for the Sustainable Development Program until 2030 due to voluntary contributions $(\%, 2019)$.

Ideas, principles, strategies and mechanisms for implementing the Sustainable Development Concept are rather deeply and consistently studied and generalized in the scientific sources. Thus, such foreign scientists as R. Solow, [9], W. Vandenhole, [10], L. Coscieme, P. Sutton [11], J. Stead, W. Stead [12] considered the sustainable development and economic growth in their scientific works. Ukrainian scientists also studied this issue, namely: W. Leontief [13], V. Makedon, O. Hetman [14], S. Makosii [15], V. Liashenko and Yu. Kharazishvili [16].

Particular attention should be paid to the works of J. Sachs, J. Leape [17], E. Barbier [18], L. Buys [19], K. Mengersen [20]. In their works the concept of sustainable development was considered to cover a triune concept for balanced economic, social, and environmental development. In this triune concept, "Nature - Society - Economy" system is considered as an aggregate.

Among the prominent foreign authors on this topic is American researcher J. Elkington [21], who proposed the business development concept, according to which entrepreneurs and managers should consider not only a firm's financial performance, but social performance and environmental impacts as well.

The theory of human capital of G. Becker [22] and the work of T. Schultz [23] on investing in human capital played a significant role in the formation of sustainable development concepts: a significant contribution was made by A. Armstrong, S. Taylot [24]; the social capital concept was developed by J. Coleman interpreted the social capital as a measure of social activity, social motivation and effectiveness of social institutions [25], that also has a essential impact on development of this concept. Later, in the scientific research of S. Johansson, the concept of "quality of life" appeared, which is considered as human's ability to manage their own lives [26]; the impact of human resource management on the efficiency of enterprise research was studied by D. Guest [27]. K. Laursen, N. Foss [28] in their works investigated the links between human resource management and innovation development; J. Delery, D. Roumpi consider sustainable development in a resource context (resource-based view (RBV), they also constantly use in their research strategic human resource management (SHRM) and reveal the potential for further research 
within the "micro - macro" interaction [29]. E. Bombiak [30] explores the issue of sustainable enterprise development under the influence of Green human resource management.

The Ukrainian scientists pay great attention to the human resources impact on an enterprise development in their researches. I. Kalenyuk and O. Grishnova [31] consider the firm development under the influence of the intellectual corporate capital formation. A. Kolot and O. Herasymenko [32] consider the development issue through socio-economic institutions development in the triad "market - state - business". The human resources innovative development issue at enterprises is investigated by O. Vlasenko, M. Sokolova [33].

The systematization of theoretical research and practical experience allowed to state, that for the stable functioning of both the economic system and an enterprise, it is necessary to implement the Sustainable Development Concept which must be built and transformed in accordance with present conditions. Therefore, innovative approaches to enterprise sustainable development management are currently needed, which can easily be understood from the viewpoint of innovation and a strong desire to exert a positive impact upon the situation with human rights and the environment protection. It also was proposed to use a descriptive research method that would explain the need to implement innovative strategies for enterprises sustainable development, namely human resource management innovative strategies. Therefore, according to the authors, the human resource is the key factor for sustainable development of enterprise.

\section{Results and discussion}

Many scientists identify three main sustainable development components: environmental, social and economic $[17,18,19,20]$. It is believed that the combination of ecological, social and economic balance $[17,18,19,20]$ should be considered not only at the macrolevel (the whole planet), but also at the micro-level (enterprises). Therefore, the Sustainable Development Concept is implemented not only globally as a national strategy, but also at the micro-level as a development strategy for a region or even for an individual enterprise as a business entity. In the view of the stability-wise concept managers should provide not only an economic growth plan for an enterprise or a high stable profit strategy, but also an action plan for harmonious coexistence of environment, enterprise and human.

A number of key indicators were studied to comprehensively consider the capability to ensure implementing the sustainable development concept in the European Union and in Ukraine due to implementation of SDG-8. The study was held in the context of identifying the place of Ukraine among the EU countries.

Firstly, we will analyse the dynamics of real GDP per capita by countries in the period of 2016-2020 (see Fig. 2) [34]. According to the results of 2016-2020, Ukraine had a slight annual increase in GDP (by $2.15 \%$ ) in average on a year-to-year basis. However, such rates are insufficient. A necessary condition for the transition to sustainable economic growth is the implementation of an active inclusive development strategy which can guarantee an annual GDP growth rate of $6-7 \%$ and growth of production volumes at least in two times. This will significantly improve the living standards of the population and will provide launching a chain transformation process towards achieving all other sustainable development goals. 


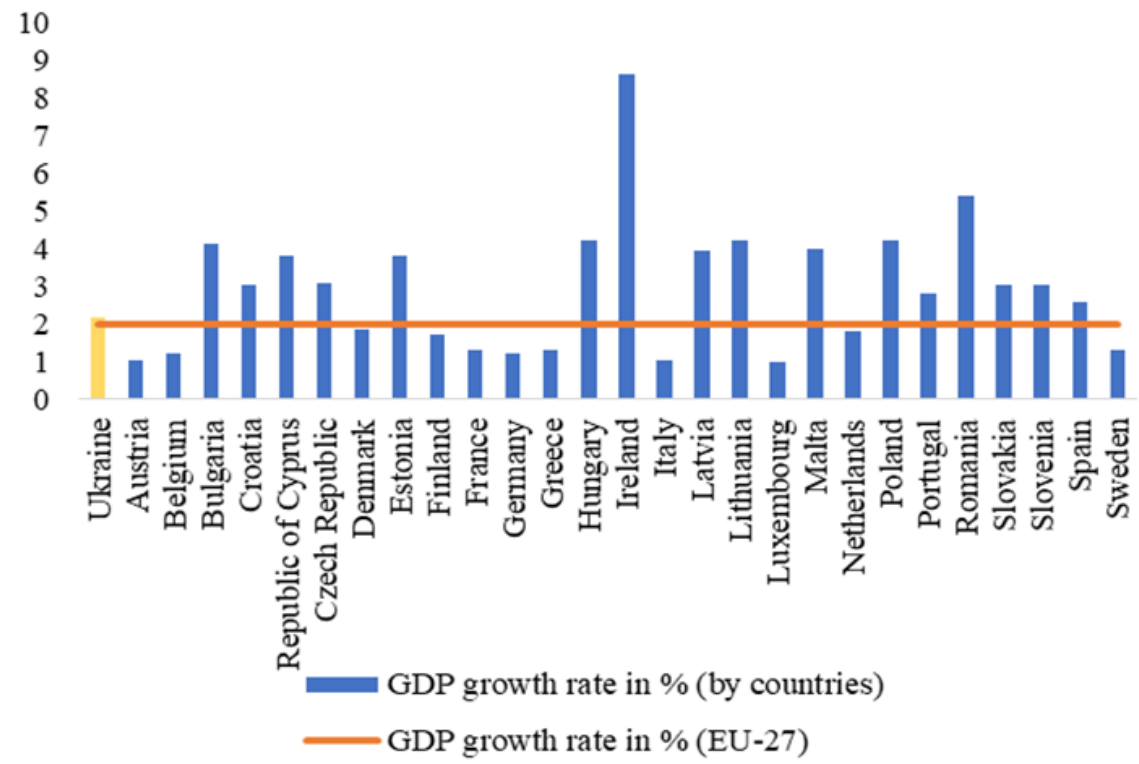

Fig. 2. The dynamics of GDP per capita by countries (average annual growth rate in \%, 2016-2020).

Secondly, the Investment share of GDP indicator should be considered as a key indicator of investments in the future (2016-2020) (see Fig. 3) [35]. As the response to the problem of limited access to financial resources in Ukraine, there has been the emergence of relatively low investment activity. The investment share in Ukraine's GDP in 2020 was the lowest since gaining independence $(9 \%)$, which is almost 2.5 times lower than in some European countries. Such relatively low investment activity hinders modernization of the national economy, reduces PP\&E turnover ratio and does not help maintaining the production capacity which is capable of creating a competitive product. As a result, it intensifies the process of ousting domestic producers from competitive markets.

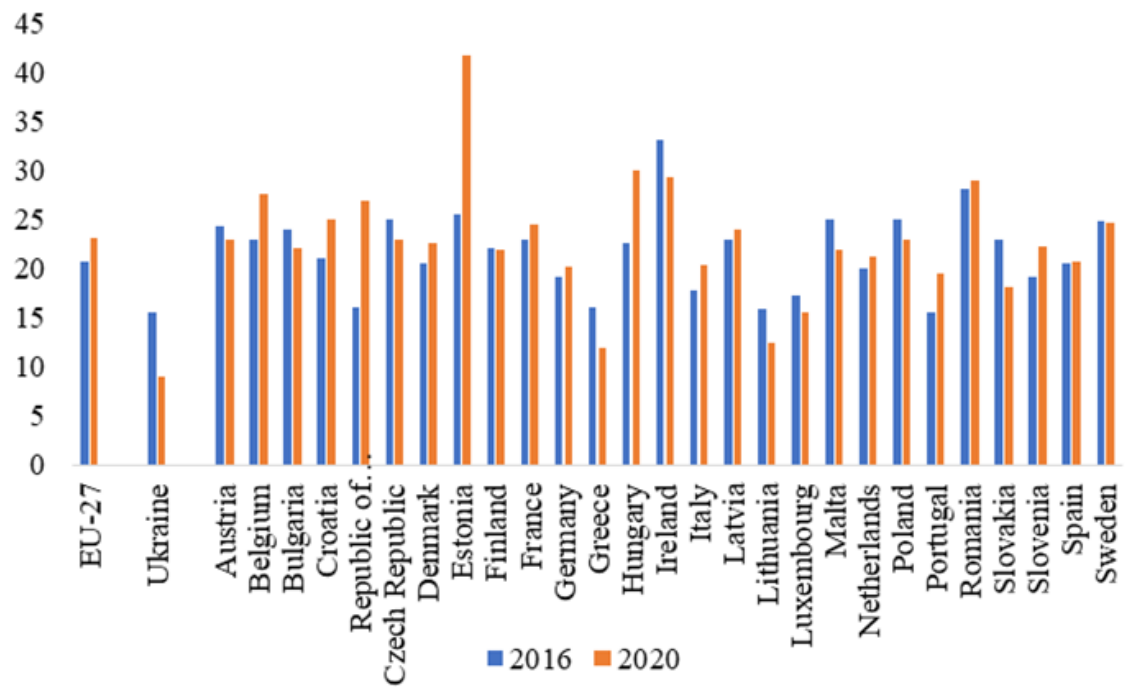

Fig. 3. Investment share of GDP by countries (\% of GDP). 
Thirdly, the level of innovations in the economic system is an important element of sustainable development. To define this level, the Global Innovation Index can be used (see Fig. 4) [36]. In 2020 Ukraine ranked 45-th among 131 countries. Nevertheless, it should be noted that 71 st position among 131 countries in the Innovation Input Sub-Index indicates a lack of investments in innovation processes. Sustainable growth is only possible if structural and innovative development model is implemented, i.e. intensive technical and technological renovation of production and use of innovative approaches to human resource management.

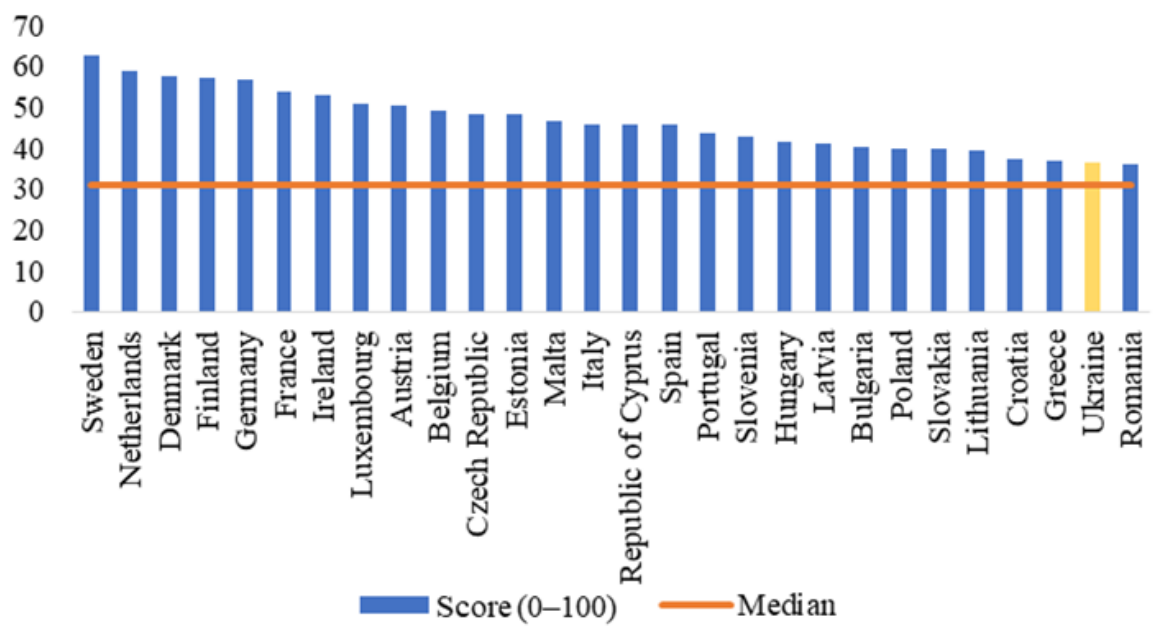

Fig 4. Global Innovation Index 2020 (EU 27 and Ukraine).

Fourthly, an important way to ensure the economic system development is to create conditions for starting and doing business, that's why the Doing Business indicator was chosen (see Fig. 5) [37]. In 2020 Ukraine ranked 64-th among 190 countries improved the results by 7 points. The current position is not bad, but it is not the best even among the post-Soviet countries. For instance, Lithuania is in 11-th position now, Estonia - in 18-th, and Latvia - in 19-th.

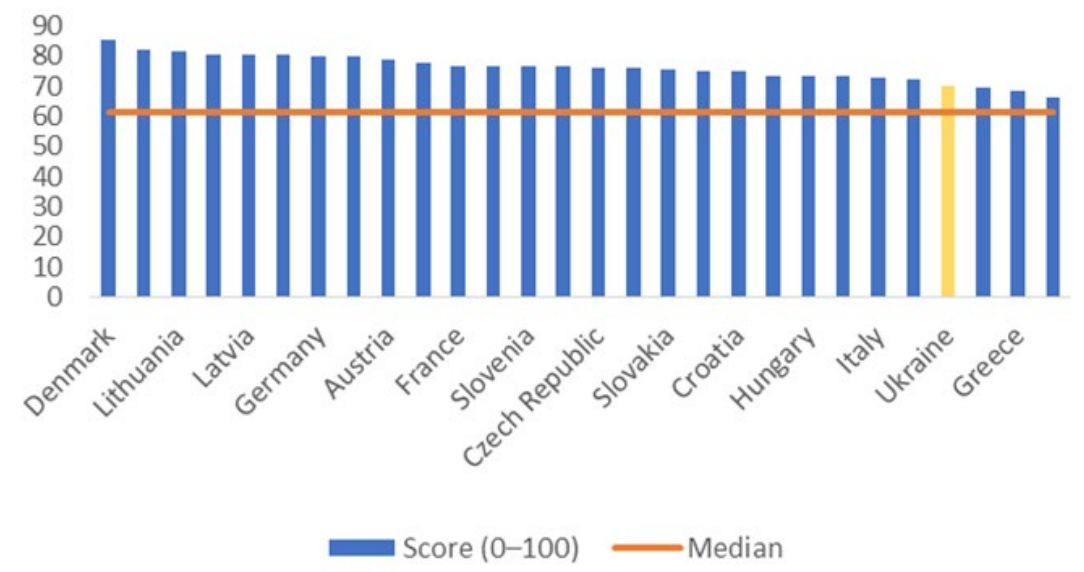

Fig. 5. Doing Business Index 2020 (EU 27 and Ukraine). 
Finally, it was decided to choose The Inclusive Development Index (IDI) as a compiling indicator which allows opportunity to consider growth and development indicators (such as GDP, labour productivity, healthy life expectancy and employment), inclusiveness (such as social stratification ratio, poverty ratio) and sustainable development (such as adjusted net savings, greenhouse intensity of GDP, public debt, demographic burden and median income). There is revealed that Ukraine was included to the group of countries with regressive dynamics by the indicator level and dynamics of development. Moreover, in this group, compared with the EU countries, it stands out not only by the level of overall indicator (15\% deviation from the group average), but also by the deceleration rate (see Fig. 6) [38].

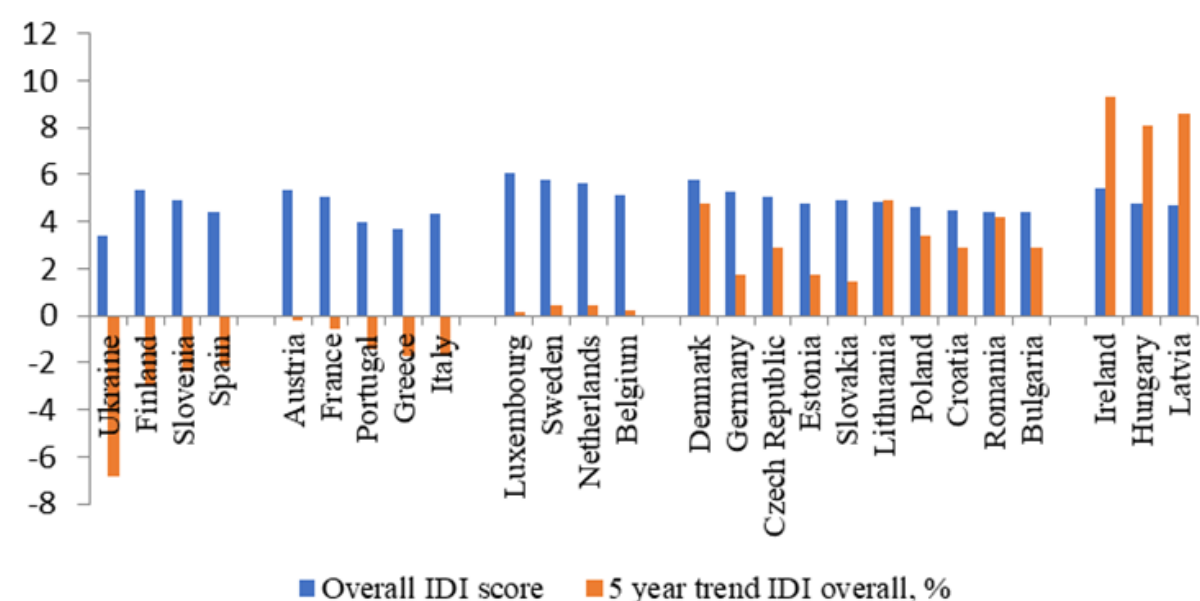

Fig. 6. The Inclusive Development Index dynamics by the group of EU countries and Ukraine.

The priority task in sustainable development concept implementation and especially implementation of SDG-8 is ensuring decent work, economic growth, and lowering deceleration rate. This can be achieved by using the inclusive component providing decent working conditions and the income convergence of population, reducing emissions, raising awareness of environmental issues among population and improving business conditions.

At the same time, the human resource is the basis for the state economy and economic transformations in Ukrainian enterprises. Safe work and decent wages should meet all human needs in order to achieve adequate quality of life, well-being and prosperity.

The analytical studies made by the authors on the implementation of the Sustainable Development Concept allowed to propose the following classification of sustainability levels (see Fig. 7). This understanding, interpretation and detailing of sustainability levels indicates not only on complexity and on multidimensionality of this concept, but also reveals incompleteness of sustainability study process, manifesting the essence and achieving unambiguity in its interpretation both by researchers and practitioners. 


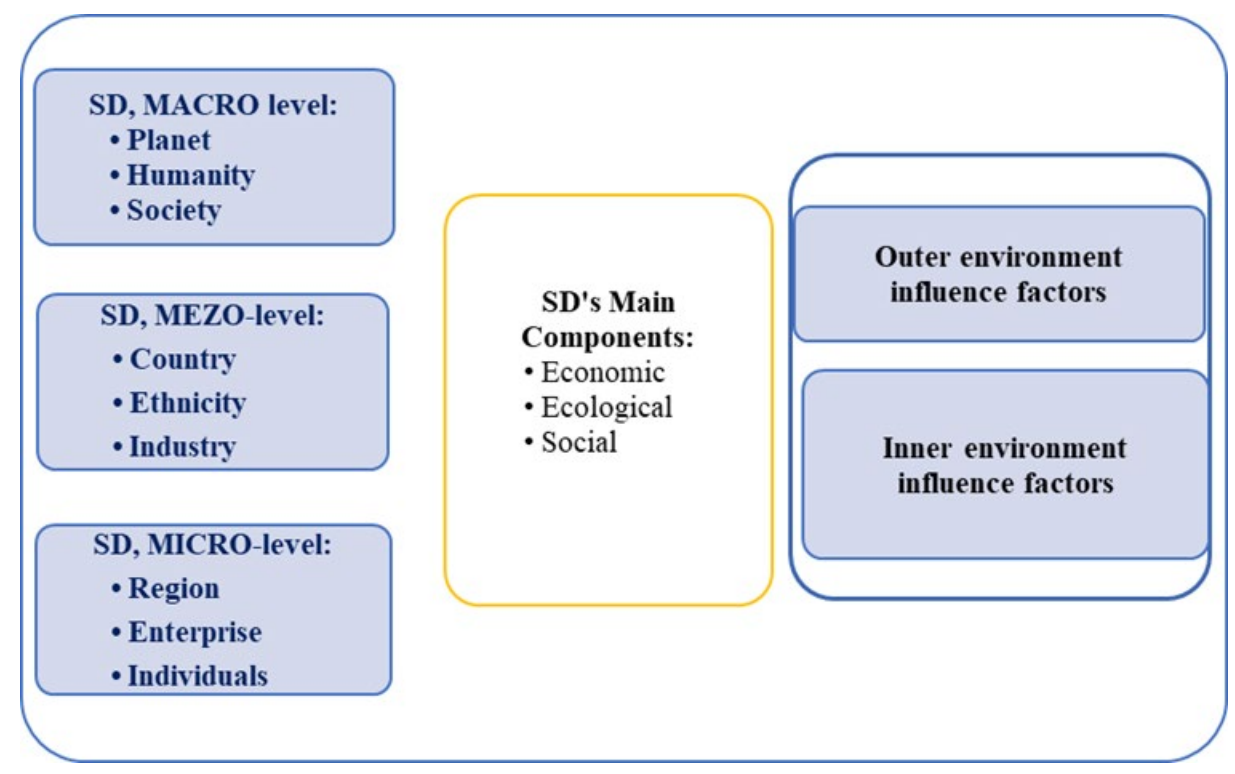

Fig. 7. Classification of stability levels.

Ukrainian business is not in arrearages of the integration into global sustainable development processes. There is the network of Global Compact Network Ukraine - the official platform of the United Nation Global Compact [39]. It is a special initiative of the UN Secretary General and the world's largest association of corporately responsible business which encourages companies to develop their activities and strategies in accordance with the Sustainable Development Goals and based on ten universal principles in human rights, labour and environment, as well as anti-corruption fields. The organization includes almost 13,000 commercial companies and 3,000 non-business organizations in 69 local networks located in 160 countries. The Ukrainian Network has 80 members.

The UN Global Compact Network in Ukraine is a dialogue and training platform for sustainable development for business, investors, society, labour organizations, local authorities and the government.

It is worth focusing on the program Young SDG Innovators provided by the United Nation Global Compact [40]. Alfa-Bank Ukraine, DTEK, Energoatom, PUMB, Farmak, Astarta-Kyiv, EPAM, EY Ukraine, FILM.UA Group, YesStraws, Caparol of Ukraine participated in this initiative in Ukraine. The main SDGs supported by this initiative are SDG-8 - decent work and economic growth, SDG-9 - industry, innovation and infrastructure, SDG-11 - sustainable cities and communities, SDG-17 - partnership for sustainable development.

Based on progressive Ukrainian business experience, theoretical research of foreign and Ukrainian scientists, as well as with consideration of progressive experience of companies, a cycle of enterprise sustainable development management was formed (Fig. 8). 


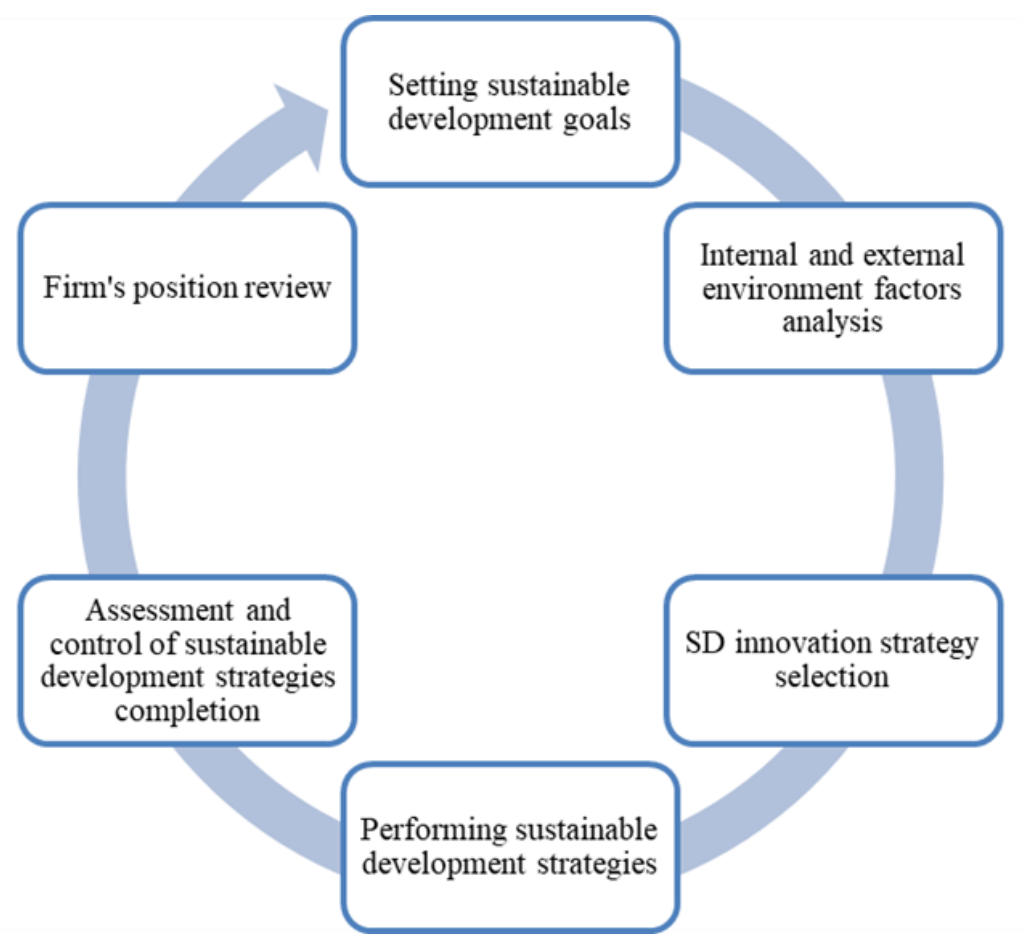

Fig. 8. Enterprise SD management cycle.

Each presented cycle element requires certain and well-known instruments for its implementation. At the same time the specifics of the sustainable development goals place different emphasis on the priorities of the tasks to solve.

As a result of such generalization, it is possible to clarify the concept of "business sustainable development" as a cycle of important goals and innovative management strategies continuous decomposition. These strategies characterize the economic, environmental, social or other firm's components and tasks, which allows using resources as efficiently and long as possible without harming the environment and the interests of current and future generations.

This definition, in contrast to the existing ones, emphasizes not only firm's economic component, but also environmental and, most importantly, social.

It can be stated that in conditions of unstable external environment and high competition, the internal business environment should become a support for business sustainable development. Strategies for managing business sustainable development from the internal business environment include:

- Financial management strategy;

- Material resources management strategy;

- Optimal decisions making strategy;

- Human resources management strategy.

It should be noted that all strategies ought to be developed through the prism of innovation and the striving to have a positive impact on human rights and the environment.

In modern conditions the human resources management strategy comes first among sustainable development management strategies, i.e. achieving sustainable development is possible only with a team of like-minded people and only with implementation of optimal business processes in terms of achieving sustainable development goals. 
The human resources management strategy plays a special and highly important role in implementation of sustainable development concept. People can be a source of innovative ideas which can be applied by the company in future. Moreover, human factor in modern information society can influence on a business sustainable development both positively and negatively.

Human resource management processes should be focused not only on operational activities, but also on improving the personal competitiveness of employees, which will form corporate knowledge through the development of corporate universities and Elearning systems [33], and it will be the main instrument for sustainable enterprise development. However, one more important factor of sustainable development is the formation of an appropriate organizational culture and stimulation of both intra-firm and inter-firm collaboration as a source of shared experiences and healthy business environment formation. Achieving this goal, the process is also facilitated by innovative forms of social business organization creating innovative instruments for solving and financing social problems. The key elements for them are human resource management and effective use of human resources.

The most important elements of human resource management are staff selection solution, staff adaptation, career planning, as well as employee training. In the process of personnel selection, such as the applicant's resume analysis, preliminary acquaintance, including phone interview with the candidate, remote testing, personal interview with HRmanagers, interview with the head, the candidate's compliance with qualification requirements, the ability to percept corporate principles and career prospects based on professional and personal characteristics are evaluated.

After hiring a candidate the adaptation process takes effect, it includes preparing and transferring work tasks to a new employee. An instructor or mentor, who shares common experience in performing operations, as well as the company's principles and behaviour patterns, should accompany each employee. Human resources department at this stage should conduct introductory training for employees to familiarize them with the corporate culture, norms and procedures.

Particular attention should be paid to the process of an employee's career planning, as well as to development of his/her competencies. The company should work on creating a succession culture, i.e. filling the leading positions by internal employees, because it is succession ensures preservation of history, traditions, experience and the guide that contributes to enterprise sustainable development.

It is important to notify that employees do not always understand benefits of such instrument at once and often consider it as a futile process.

Possible methods of increasing employee involvement may be:

1) Work in cross-functional teams, where employees have opportunities to realize their potential and feel significance;

2) Open portal development, on which success and development stories of employees working in the organization are published;

3) Support from managers, delegation of new tasks that can develop the employee;

4) Experience and knowledge transfer between employees of one department, performed tasks rotation between employees;

5) Corporate universities and E-learning systems introduction [33] for continuous sustainable development the human resources of enterprise.

Employee training is the most important prerequisite for innovative enterprise development. For example, it can be balanced using the principle of 70/20/10 [41]. According to this model the most effective development of professional and personal competencies occurs in the course of practical activities $(70 \%)$, which are based on the relationship with other approaches, such as feedback and training (20\%), as well as formal 
training, which in turn has the lowest impact on the completeness and speed of employee development (10\%). Thus, the entity applies different approaches to employee development to get the most out of the potential. Work efficiency evaluation should be based on the employee goals achievement during the year, and goals are formed in accordance with SMART goals setting technology (Specific, Measurable, Achievable, Relevant, TimeBound) $[42,43]$, i.e. goals should be specific, measurable, achievable, relevant, and related to certain time frame. The senior management goals should be interconnected, consistent and reflected in the tasks of other employees.

Motivation and incentives system should be organized in such way that the financial component of motivation reflects implementation of goals and objectives for employee. To ensure the motivation scheme transparency, it is necessary to shift the employees' focus on achieving goals, rather than on salary motivation; to introduce a grading system for all employees. Alternative ways of motivation, that have proven their effectiveness, include corporate events, events for employees and their families, competitive events with prizes.

The internal business environment, as mentioned above, is the basis of any enterprise. Functioning in the external environment is characterized by complexity and multilevel structure, and when receiving from it the necessary resources, it is impossible to ignore the processes occurring in it. The external environment influence on business activities is different and it is determined by both specific features and enterprises internal potential. As a result, companies need information about existing threats or open opportunities, analysis of direct influence factors, which will ensure adoption of reasonable management decisions and formation of adequate impact on the environment. Thus, focusing on consumers as one of the main external factors influencing the enterprise activities, we will consider some instruments for managing communications with them.

Consumers by their decisions determine the range of most desirable goods and services for them. They dictate the price thresholds at which they are willing to buy a particular product influencing the criteria of enterprise efficiency. For the company to function, it is necessary to regularly analyse and respond to the needs of its customers.

To ensure long-term, innovative, sustainable enterprise' operation it is necessary to constantly analyse a market, recognize capabilities, determine the range of competitors and consumers, and develop effective response methods. In the present society development conditions, the internal change driver is a human resource of an enterprise, and external driver is consumers. Therefore, satisfaction of employees and consumers will be the key to sustainable and continuous enterprise growth. In general, sustainable development over time with consideration of proposed approaches can be represented as a modified production function:

$$
\frac{\mathrm{d} \varphi(\mathrm{H} ; \mathrm{F} ; \mathrm{M} ; \mathrm{C})}{\mathrm{d} t} \geq 0
$$

where $\varphi(\mathrm{H} ; \mathrm{F} ; \mathrm{M} ; \mathrm{C})$ - revenue function of using resources, $\mathrm{H}$ - human resources, $\mathrm{F}-$ financial resources, $\mathrm{M}$ - material resources, $\mathrm{C}-$ communication with consumers, $\mathrm{t}$ - time period.

Thus, significant attention in the enterprise sustainable development concept as part of the economic system should be paid to developing an efficient human capital management strategy, which is focused on such goals as decomposition in sustainable development, a favourable organizational culture development, business models formation based on effective communication with consumers, choosing the newest organization forms and doing business practices including those that have emerged in the field of social business, which will allow to move towards realization of main sustainable development goals. 


\section{Conclusions}

Further functioning of the enterprise and its activities expansion require improvement of the applied management instruments. While in the recent past they were focused only on the financial component of performance, then over time, understanding of inadequacies and imperfections of this approach emerged. Today, managers of many companies consider sustainable development concept as a modern and effective management approach. On the one hand, in order to implement it, the company's business processes that provide optimization of financial, material, and human resources, and the employees who share the sustainable development principles are able to implement them, should be the basis. On the other hand, influence on the consumer and, to some extent, his/her education within the traditions of environmental and health protection strengthens the company's orientation to achieve sustainable development goals, and then to use its principles by maintaining a balance between economic, environmental and social business components.

The human resource management primarily involves defining common goals and facilitating their perception by the company's staff through corporate culture, communication with management, and other awareness-raising activities. All activities at this level should be planned and aligned with the company's overall goals.

The coordinating component of human resources management is represented by a firm's personnel policy, and thus it should be consistent with the firm's goals of sustainable development.

An important component of human resource management is developing an effective motivation system that will encourage employees to care not only about their own needs, but also about the needs of future generations, thus participating actively in solving social problems.

\section{References}

1. United Nations (1983). Resolution of United Nations: Process of preparation of the Environmental Perspective to the Year 2000 and Beyond. https://undocs.org/en/A/RES/38/161

2. United Nations (1992). Report of the United Nations Conference on Environment and Development. https://undocs.org/en/A/CONF.151/26/Rev.1(vol.I)

3. United Nations Millennium Declaration. (2000). undocs.org. https://undocs.org/en/A/RES/55/2

4. United Nations (2000). The Millennium Summit. https://www.un.org/en/events/pastevents/millennium summit.shtml

5. The Sustainable Development Goals. (n.d.). https://sdgs.un.org/goals

6. UN (2015). Transforming our world: the 2030 Agenda for Sustainable Development. https://www.un.org

7. Voluntary contributions 2019. (2019). https://rm.coe.int/voluntary-contributions-2019web-en-final/16809fflfe/

8. United Nations Statistics Division. (2020). The Sustainable Development Goals Report 2020. https://unstats.un.org/sdgs/report/2020/

9. Solow, Robert M. (1956). A Contribution to the Theory of Economic Growth. The Quarterly Journal of Economics, 70(1), 65-94. https://doi.org/10.2307/1884513

10. Vandenhole, W. (2018). De-Growth and Sustainable Development: Rethinking Human Rights Law and Poverty Alleviation. Law and Development Review, 11(2), 647-675. https://doi.org/10.1515/ldr-2018-0033

11. Coscieme, L., Sutton, P., Mortensen, L. F., Kubiszewski, I., Costanza, R., Trebeck, K., Pulselli, F. M., et al. (2019). Overcoming the Myths of Mainstream Economics to 
Enable a New Wellbeing Economy. Sustainability, 11(16), 4374. http://dx.doi.org/10.3390/su11164374

12. Stead, J.G., Stead, W.E. (2019) Why Porter Is Not Enough: Economic Foundations of Sustainable Strategic Management. In: Wunder T. (eds). Rethinking Strategic Management. CSR, Sustainability, Ethics \& Governance. Springer, Cham. https://doi.org/10.1007/978-3-030-06014-5 4

13. Leontief, W. (1977). The future of the world economy. Socio-Economic Planning Sciences, 11(3), 171-182. https://doi.org/10.1016/0038-0121(77)90036-2

14. Makedon, V., Hetman, O., Yemchuk, L., Paranytsia, N., \& Petrovska, S. (2019). Human resource management for secure and sustainable development. Journal of Security \& Sustainability, 8(3). http://doi.org/10.9770/jssi.2019.8.3(5)

15. Makosii, S. (2016). Foreign experience in implementing a sustainable development strategy. Molodyi vchenyi - Young scientist, 6, 324-328.

16. Liashenko, V., \& Kharazishvili, Yu. (2016). Strategic scenarios of structural development of industrial regions of Ukraine. Visnyk ekonomichnoi nauky Ukrainy Bulletin of Economic Science of Ukraine, 2(31), 113-126.

17. Sachs, J., Leape, J. (2015). The Age of Sustainable Development. International Growth Centre public lecture. lse.ac.uk. https://www.lse.ac.uk/Events/EventsAssets/PDF/2015/20150204-Jeff-Sachs-PPT.pdf

18. Barbier, E. B. (2013). Economics, natural-resource scarcity and development (Routledge revivals): Conventional and alternative views. Routledge.

19. Buys, L., Burton, L., Cuthill, M., Hogan, A., Wilson, B., \& Baker, D. (2015). Establishing and maintaining social connectivity: An understanding of the lived experiences of older adults residing in regional and rural communities. The Australian journal of rural health, 23(5), 291-294. https://doi.org/10.1111/ajr.12196

20. Buys, L., Mengersen, K., Johnson, S., van Buuren, N., \& Chauvin, A. (2014). Creating a Sustainability Scorecard as a predictive tool for measuring the complex social, economic and environmental impacts of industries, a case study: assessing the viability and sustainability of the dairy industry. Journal of environmental management, 133, 184-192. https://doi.org/10.1016/j.jenvman.2013.12.013

21. Elkington, J. (2020). Green Swans: The Coming Boom in Regenerative Capitalism (Kindle ed.). Fast Company Press: New York, NY, USA.

22. Backer, G.S. (1962). Investment in Human Capital: A Theoretical Analisis. The Journal of political economy, 70(5), 9-49.

23. Schultz, T. (1971). Investment in Human Capital: The Role of Education and of Research. New York: Free Press.

24. Armstrong, M., Taylor, S. (2020) Armstrong's handbook of human resource management practice (15th Ed). London: Kogan Page.

25. Coleman, J. (1988). Social Capital in the Creation of Human Capital. American Journal of Sociology, 94, 95-120. http://www.jstor.org/stable/2780243

26. Johansson, S. (2002). Conceptualizing and Measuring Quality of Life for National Policy. Social Indicators Research, 58, 13-32. https://doi.org/10.1007/0-306-47513-8_2

27. Guest, D. E. (2011). Human resource management and performance: still searching for some answers. Human Resource Management Journal, 21(1), 3-13. https://doi.org/10.1111/j.1748-8583.2010.00164.x

28. Laursen, K., \& Foss, N. J. (2013). Human Resource Management Practices and Innovation. Oxford Handbooks Online. https://doi.org/10.1093/oxfordhb/9780199694945.013.009

29. Delery, J. E., \& Roumpi, D. (2017). Strategic human resource management, human capital and competitive advantage: is the field going in circles? Human Resource Management Journal, 27, 1-21. https://doi.org/10.1111/1748-8583.12137 
30. Bombiak, Edyta. (2018). Green Human Resource Management as a Tool for the Sustainable Development of Enterprises: Polish Young Company Experience. Sustainability, 10(6), 1739. https://doi.org/10.3390/su10061739

31. Kalenyuk, I., Grishnova, O., Tsymbal, L., Djakona, A., \& Panchenko, E. (2020). Formation of intellectual corporatecapital: methods and moderntrends. Bulletin the National academy of sciences of the Republic of Kazakhstan, 1(383), 182-191. https://doi.org/10.32014/2020.2518-1467.23

32. Kolot, A. \& Herasymenko, O. (2017). Market, state and business in coordinates of the new economy. Problems and Perspectives in Management (open-access), 15(3), 76-97. https://doi.org/10.21511/ppm.15(3).2017.07

33. Zhykharieva, V., Vlasenko, O., \& Sokolova, M. (2020). The Principles of Innovative Human Resource Management. Modern Economics, 21(2020), 89-94. Retrieved from https://doi.org/10.31521/modecon.V21(2020)-14

34. European Commission (n.d.). Real GDP per capita. https://ec.europa.eu/eurostat/databrowser/view/sdg_08 10/default/table?lang=en

35. CEICDATA (n.d.). Investment: $\%$ of GDP by Country Comparison. https://www.ceicdata.com/en/

36. The Global Innovation Index. (n.d.). https://www.globalinnovationindex.org/analysisindicator

37. Doing Business (n.d.). https://www.doingbusiness.org/en/doingbusiness

38. The Inclusive Development Index 2018. (n.d.). www.weforum.org. https://www.weforum.org/reports/the-inclusive-development-index-2018

39. Global Compact Network Ukraine. (n.d.) https://globalcompact.org.ua/english

40. Globalcompact Young (n.d.). SDG Innovators Programme. https://globalcompact.org.ua/projects/young-sdg-innovators-programme

41. Charles, J., Jérôme W. (2011). Effective Learning with 70:20:10. The new frontier for the extended enterprise. https://alberonpartners.com/wpcontent/uploads/2019/09/Alberon_Wargnier 2011-70-20-10 vEN.pdf

42. Ogbeiwi, O. (2017). Why written objectives need to be really SMART. British Journal of Healthcare Management, 23, 324-336. https://doi.org/10.12968/bjhc.2017.23.7.324

43. Chan, M. Y., Swann, C., \& Donnelly, J. (2018). Are S.M.A.R.T goals really smart? The psychological effects of goal-setting in a learning task. Frontiers in Psychology, 9. https://doi.org/10.3389/conf.fpsyg.2018.74.00020 